\title{
Sphingosine kinase 1 contributes to doxorubicin resistance and glycolysis in osteosarcoma
}

\author{
XIAOJUN REN ${ }^{1}$ and CHUNHONG SU ${ }^{2}$ \\ Departments of ${ }^{1}$ Pediatric Orthopedics and ${ }^{2}$ Pain, Lanzhou University Second Hospital, Lanzhou, Gansu 730000, P.R. China
}

Received August 17, 2019; Accepted March 2, 2020

DOI: $10.3892 / \mathrm{mmr} .2020 .11295$

\begin{abstract}
Osteosarcoma (OS) is one of the most common and aggressive malignancies in children and adolescents worldwide. Sphingosine kinase 1 (SphK1) has recently been reported to serve a role in OS progression. The present study aimed to investigate the role of SphK1 in the development of chemoresistance and glycolysis in OS cell lines. SphK1 expression levels in OS cell lines (U2OS, MG63 and SaoS2) were analyzed using western blotting and reverse transcription-quantitative PCR (RT-qPCR). A cell survival assay was conducted to determine doxorubicin-resistance in OS cells, and glycolysis was also evaluated. SphK1 expression was increased in the U2OS and SaoS2 cell lines, and both cell lines were more resistant to doxorubicin when compared with the MG63 cell line. SphK1 knockdown or overexpression altered doxorubicin resistance and the viability of OS cell lines. In addition, hypoxia inducible factor- $1 \alpha$ (HIF-1 $\alpha$ ) expression was positively associated with SphK1 expression, and partly mediated SphK1-induced effects on doxorubicin resistance and glycolysis. The present study suggested that SphK1 participated in the development of doxorubicin resistance and contributed to glycolysis in OS cells by regulating HIF-1 $\alpha$ expression. However, further studies investigating the application of SphK1 associated therapies for patients with OS are required.
\end{abstract}

\section{Introduction}

Osteosarcoma (OS), a type of bone cancer, is one of the most common and aggressive malignancies in children and adolescents worldwide (1). The clinical benefits of existing therapeutic strategies for OS are unsatisfactory, despite significant developments in diagnostics and treatments during the last few decades $(2,3)$. The majority of patients with OS experience recurrence and poor prognosis following surgical

Correspondence to: Mr. Xiaojun Ren, Department of Pediatric Orthopedics, Lanzhou University Second Hospital, 80 Cuiyingmen, Lanzhou, Gansu 730000, P.R. China

E-mail: renxiaojun2010@2980.com

Key words: sphingosine kinase 1, resistance, osteosarcoma, hypoxia inducible factor-1 $\alpha$ resection or adjuvant chemotherapy (4). Previous studies have revealed that the high recurrence rate of OS is primarily due to chemoresistance to anti-OS therapy (5). Aberrant alterations to certain proteins and genes are partly responsible for chemoresistance in OS cells (6). He et al (1) summarized the major mechanisms of chemoresistance in OS, including decreased intracellular drug accumulation, drug inactivation, enhanced DNA repair, perturbations in signal transduction pathways, apoptosis and cell cycle-associated gene expression turbulence, autophagy-associated chemoresistance, microRNA dysregulation and cancer stem cell-associated drug resistance.

Sphingosine kinases are lipid kinases that catalyze the production of sphingosine-1-phosphate (S1P) by phosphorylating sphingosine, a process that regulates cell proliferation, motility, differentiation, apoptosis and angiogenesis (7). A number of studies have reported a role for sphingosine kinases in tumor progression, in particular sphingosine kinase 1 (SphK1) (8-12). Zhao et al (13) reported that SphK1 promoted metastasis by activating the $\mathrm{S} 1 \mathrm{P} / \mathrm{S} 1 \mathrm{P}$ receptor $3 /$ Notch cascade in thyroid carcinoma. Another study reported that SphK1 inhibited melanoma growth in a mouse model (14). SphK1 has also been reported to be overexpressed in multiple cancer cell lines, and to be associated with resistance to chemotherapy (15) and glycolysis promotion $(16,17)$. Targeting SphK1 has been identified as a promising and effective anticancer therapeutic strategy for the treatment of multiple types of cancer, including gastric (18) and colorectal cancer (19), as well as nasopharyngeal (20) and hepatocellular carcinoma (21). Yao et al (22) reported that co-administration of doxorubicin and phenoxodiol synergistically inhibited proliferation both in vivo and in vitro, which suggested that SphK1-induced chemoresistance in OS could be reversed by inhibiting the activity of SphK1 (22). However, the precise molecular mechanisms of SphK1 are not completely understood; therefore, further investigation is required to identify whether SphK1 may serve as a potential therapeutic target for OS.

The present study aimed to investigate the potential role and underlying mechanisms of SphK1 in the chemoresistance and glycolysis of OS.

\section{Materials and methods}

Cell culture. The human OSU2OS, MG63 and SaoS2 cell lines and the normal human osteoblast hFOB1.19 cell line were purchased from The Cell Bank of Type Culture Collection of 
the Chinese Academy of Sciences. The cells were maintained in RPMI-1640 medium (HyClone; Cytiva) supplemented with $10 \%$ fetal bovine serum (HyClone; Cytiva) at $37^{\circ} \mathrm{C}$ with $5 \% \mathrm{CO}_{2}$.

$R N A$ extraction and reverse transcription-quantitative PCR $(R T-q P C R)$. Total RNA of cells was isolated using TRIzol ${ }^{\circledR}$ (Thermo Fisher Scientific, Inc.) according to the manufacturer's protocol. The quality and concentration of total RNA were determined using a NanoDrop spectrophotometer (Thermo Fisher Scientific, Inc.). Total RNA was reverse transcribed to cDNA using the PrimeScript ${ }^{\mathrm{TM}}$ RT-PCR kit (Takara Bio, Inc.). Subsequently, qPCR was performed using SYBR green reagent (CoWin Biosciences) following the manufacturer's protocol. Thermocycling conditions were: Initial denaturation step at $95^{\circ} \mathrm{C}$ for $5 \mathrm{~min}$, followed by 40 cycles of $10 \mathrm{sec}$ at $95^{\circ} \mathrm{C}$ for denaturation and $60 \mathrm{sec}$ at $60^{\circ} \mathrm{C}$ for annealing and extension. The primer pairs targeting human SphK1 and GAPDH were designed using Primer 5.0 (http://www.premierbiosoft. $\mathrm{com} /$ primerdesign/index.html), and the primer specificity was tested using Primer-BLAST (blast.ncbi.nlm.nih.gov/Blast.cgi). The sequences of the primer pairs used for qPCR are listed in Table I. mRNA levels were quantified using the $2^{-\Delta \Delta C q}$ method (23) and normalized to the internal reference gene GAPDH.RT-qPCR was performed in triplicate.

Western blotting. Total protein of all cell lines was extracted using RIPA lysis buffer (Cell Signaling Technology, Inc.). Total protein was quantified using the Bicinchoninic Acid Protein Assay kit (Pierce; Thermo Fisher Scientific, Inc.) according to the manufacturer's protocol and $20 \mu \mathrm{g}$ protein samples from each cell line were separated on 10\% SDS-PAGE and transferred to PVDF membranes. The membranes were blocked with $5 \%$ fat free milk for $1 \mathrm{~h}$ at room temperature and subsequently incubated overnight at $4^{\circ} \mathrm{C}$ with primary antibodies targeting human GAPDH (cat. no. 5174, 1:1,000, $37 \mathrm{kDa}$ ), SphK1 (cat. no. 12071, 1:1,000, 45-60 kDa) and hypoxia inducible factor-1 $\alpha$ (HIF-1 $\alpha$, cat. no. 36169, 1:1,000, $120 \mathrm{kDa}$ ); all purchased from Cell Signaling Technology, Inc.). Following washing with Tris-buffered saline containing $0.1 \%$ Tween-20, the membranes were incubated with HRP-linked anti-rabbit IgG antibody (Cell Signaling Technology, Inc., cat. no. 7074, 1:1,000) for $1 \mathrm{~h}$ at room temperature. Proteins bands were visualized using the SuperSignal ${ }^{\mathrm{TM}}$ West Dura Extended Duration Chemiluminescence substrate (Thermo Fisher Scientific, Inc.) and the ChemiDoc ${ }^{\mathrm{TM}}$ XRS + system (Bio-Rad Laboratories, Inc.). Blots were performed in triplicate. GAPDH was used as the loading control. ImageJ $(1.52 \mathrm{u}$; National Institutes of Health) was used to analyze the gray values of the bands.

Plasmid construction and transfection. Human SphK1 cDNA was amplified using oligodT primers and cloned into a pGLV3/H1/GFP + Puro vector (Biovector Science Lab, Inc.). A pGLV3/H1/GFP + Puro/scramble vector (Biovector Science Lab, Inc.) with limited homology to any known human sequences was used as the control. Small interfering (si)RNA targeting SphK1 (GGCTGAAATCTCCTTCACG) or HIF-1 $\alpha$ (CCGAAUUGAUGGGAUAUGATT) was designed and constructed by Guangzhou RiboBio Co., Ltd. Cells $\left(5 \times 10^{4} /\right.$ well) were plated into a 6 -well plate, cells were transfected with vectors $(5,800 \mathrm{bp}, 2 \mu \mathrm{g} / \mathrm{well})$ or siRNAs $(5,819 \mathrm{bp}, 100 \mathrm{nM})$ using Lipofectamine ${ }^{\circledR} 2000$ (Invitrogen; Thermo Fisher Scientific, Inc.), according to the manufacturer's protocol. After culturing for 2 days, the cells were used for the following experiments.

Detection of glucose uptake, lactate production and cellular ATP level. The glucose uptake assay was performed using the Glucose Uptake Assay kit (cat. no. ab136955; Abcam) and the lactate production assay was performed using the L-Lactate Assay kit (cat. no. ab65331; Abcam), both according to the manufacturer's protocol. Cellular ATP levels were measured using the ATP Assay kit (cat. no. ab83355; Abcam), according to the manufacturer's protocol. All assays were performed in triplicate.

Survival assay. For the cell survival assay, $4 \times 10^{3}$ cells/well were plated into a flat bottom 96-well plate with $100 \mu 1$ RPMI-1640 medium (HyClone; Cytiva) in triplicate. After $24 \mathrm{~h}$ incubation at $37^{\circ} \mathrm{C}$, cells were treated with doxorubicin $(0.001-10 \mu \mathrm{g} / \mathrm{ml}$, cat. no.S1208, Selleck Chemicals) for $72 \mathrm{~h}$ at $37^{\circ} \mathrm{C}$. Subsequently, $10 \mu 1$ Cell Counting Kit- 8 reagent following the manufacturer's protocol (Dojindo Molecular Technologies, Inc.) was added into each well. The optical density (OD) value was recorded at a wavelength of $450 \mathrm{~nm}$ using a microplate reader.

Statistical analysis. All statistical analyses were performed using SPSS software (version 21.0; IBM Corp.). Data are presented as the mean \pm standard deviation. A Student's unpaired t-test was used for the comparison of two groups. One-way ANOVA followed by Tukey's post hoc test was used for the comparison of $>2$ groups. $\mathrm{P}<0.05$ was considered to indicate a statistically significant difference.

\section{Results}

SphK1 is associated with resistance to doxorubicin in OS cell lines. To investigate the role of SphK1 in resistance to doxorubicin in OS, the expression of SphK1 in the 3OSU2OS, MG63 and SaoS2 cell lines and the normal human osteoblast hFOB1.19 cell line was determined using RT-qPCR and western blotting. The U2OS and SaoS2 cells exhibited increasedlevels of SphK1 expression compared with the hFOB1.19 and MG63 cells (Fig. 1A and B). To assess whether the aberrant expression of SphK1 was associated with doxorubicin resistance in lines, a cell survival assay was performed on cells incubated with increasing concentrations of doxorubicin $(0.001-10 \mu \mathrm{g} / \mathrm{ml})$ for $72 \mathrm{~h}$. U2OS and SaoS2 cells exhibited greater resistance to doxorubicin compared with MG63 cells (Fig. 1C). Furthermore, these results suggested that there might be a positive association between SphK1 expression and doxorubicin resistance. Collectively, the results suggested that increased SphK1 expression levels were associated with the doxorubicin-resistant phenotype of OS cell lines.

Effects of SphK1 on resistance to doxorubicin in OS cell lines. To investigate whether SphK1 downregulation in OS cell lines decreased resistance to doxorubicin, siRNAs were used to knock down endogenous expression of SphK1 in the U2OS and SaoS2 cells. Successful SphK1 knockdown was confirmed 
Table I. Primers used for reverse transcription-quantitative PCR.

Sequence (5'-3')

\begin{tabular}{lll}
\cline { 2 - 3 } Gene & \multicolumn{1}{c}{ Forward } & \multicolumn{1}{c}{ Reverse } \\
\hline GAPDH & GGTGAAGGTCGGAGTCAACG & ACCATGTAGTTGAGGTCAATGAAGG \\
SphK1 & GGAGGAGGCAGAGATAAC & TTAGCCCATTCACCACTTCA
\end{tabular}

SphK1, sphingosine kinase 1 ; HIF-1 $\alpha$, hypoxia inducible factor- $1 \alpha$.
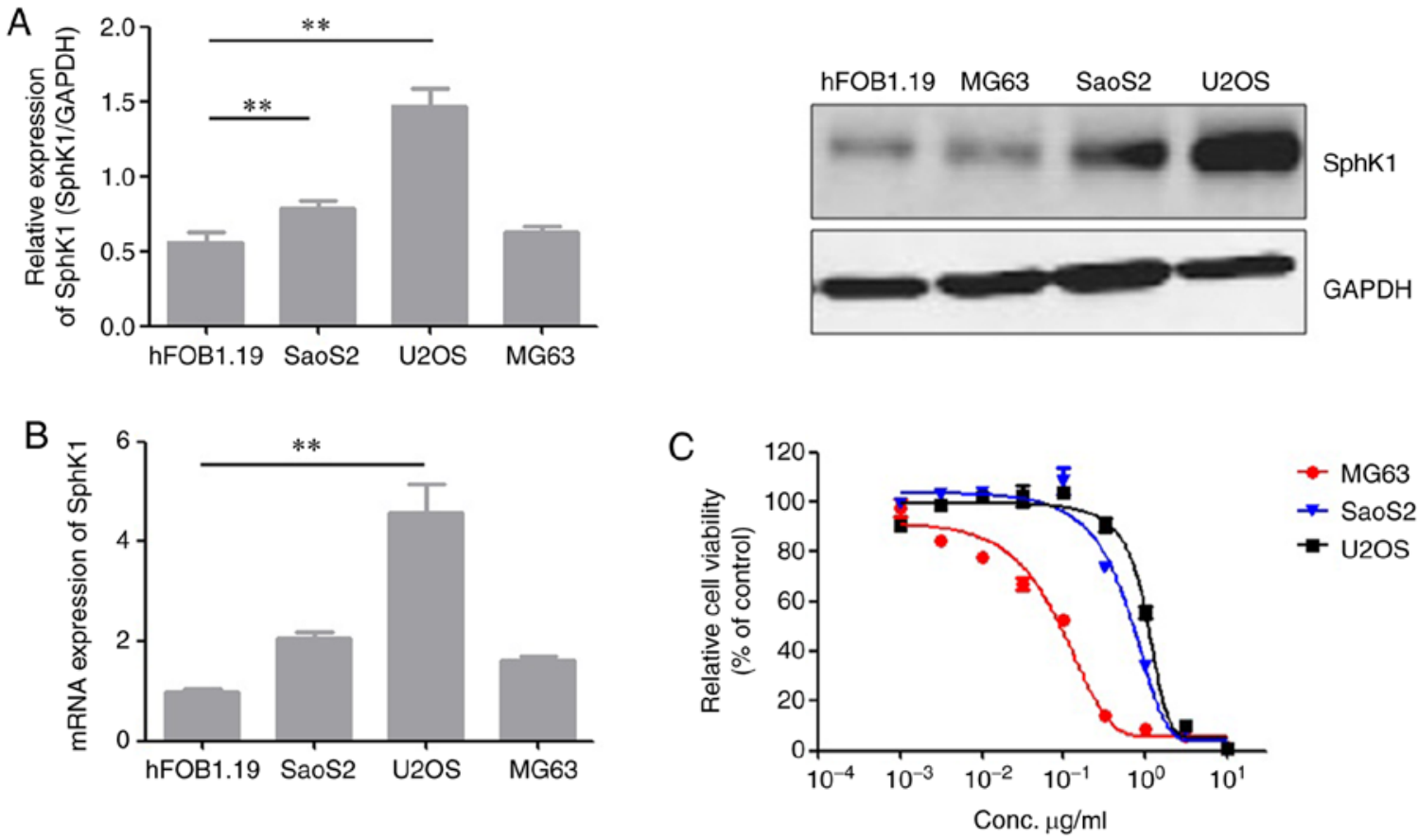

Figure 1. Doxorubicin sensitivity and SphK1 expression in OS cell lines. (A) Western blotting and (B) reverse transcription-quantitative PCR were used to detect SphK1 expression levels in OS cell lines. (C) OS cell lines were treated with different concentrations of doxorubicin for $72 \mathrm{~h}$. Subsequently, the Cell Counting Kit-8 assay was performed to measure cell viability. ${ }^{* *} \mathrm{P}<0.01$. SphK1, sphingosine kinase 1; OS, osteosarcoma.

by western blotting (Fig. 2A). Subsequently, a cell survival assay was performed to evaluate the effect of SphK1 on doxorubicin resistance. SphK1 knockdown decreased doxorubicin resistance in both U2OS and SaoS2 cells compared with the control cells (Fig. 2B). Based on the hypothesis that SphK1 was important for maintaining doxorubicin resistance in OS cell lines, the effect of increasing SphK1 expression on doxorubicin resistance in OS cell lines was investigated. MG63 cells overexpressing SphK1 were constructed, and successful transfection was confirmed by western blotting (Fig. 2C). Doxorubicin resistance was increased in MG63 cells overexpressing SphK1 compared with MG63 control cells (Fig. 2D). Collectively, the results suggested that SphK1 had a role in the generation of doxorubicin resistance in OS cell lines.

SphK1 contributes to OS cell glycolysis. To investigate the effect of SphK1 on glycolysis, glucose uptake, lactate production and cellular ATP levels were determined. SphK1 knockdown SaoS2 and U2OS cells displayed significantly decreased glucose uptake, lactate production and cellular ATP levels compared with the corresponding control cells (Fig. 3A). By contrast, glucose uptake, lactate production and cellular ATP levels were significantly increased in MG63 cells overexpressing SphK1 compared with the MG63 control cells (Fig. 3B). The results suggested an important role for SphK1 in OS cell glycolysis.

SphK1-associated effects on glycolysis and doxorubicin-resistance are mediated by HIF-l $\alpha$. The underlying mechanisms of the SphK1-associated effects were investigated. HIF-1 $\alpha$ expression was detected in OS cells by western blotting, and the HIF-1 $\alpha$ expression pattern in OS cells was similar to that of SphK1 (Fig. 4A). SphK1 over expression significantly incre-ased HIF-1 $\alpha$ expression levels in MG63 cells compared with MG63 cells transfected with control vector (Fig. 4B). Based on the suggestion that SphK1 may contribute to glycolysis and doxorubicin resistance in MG63 cells, siRNAs were used to knockdown HIF-1 $\alpha$ expression levels in MG63 and U2OS cells (Fig. 4C). The survival assay suggested that MG63 cells transfected with si-HIF-1 $\alpha$ were more sensitive to doxorubicin compared with MG63 cells transfected with si-NC (Fig. 4D). Additionally, doxorubicin resistance was 
A
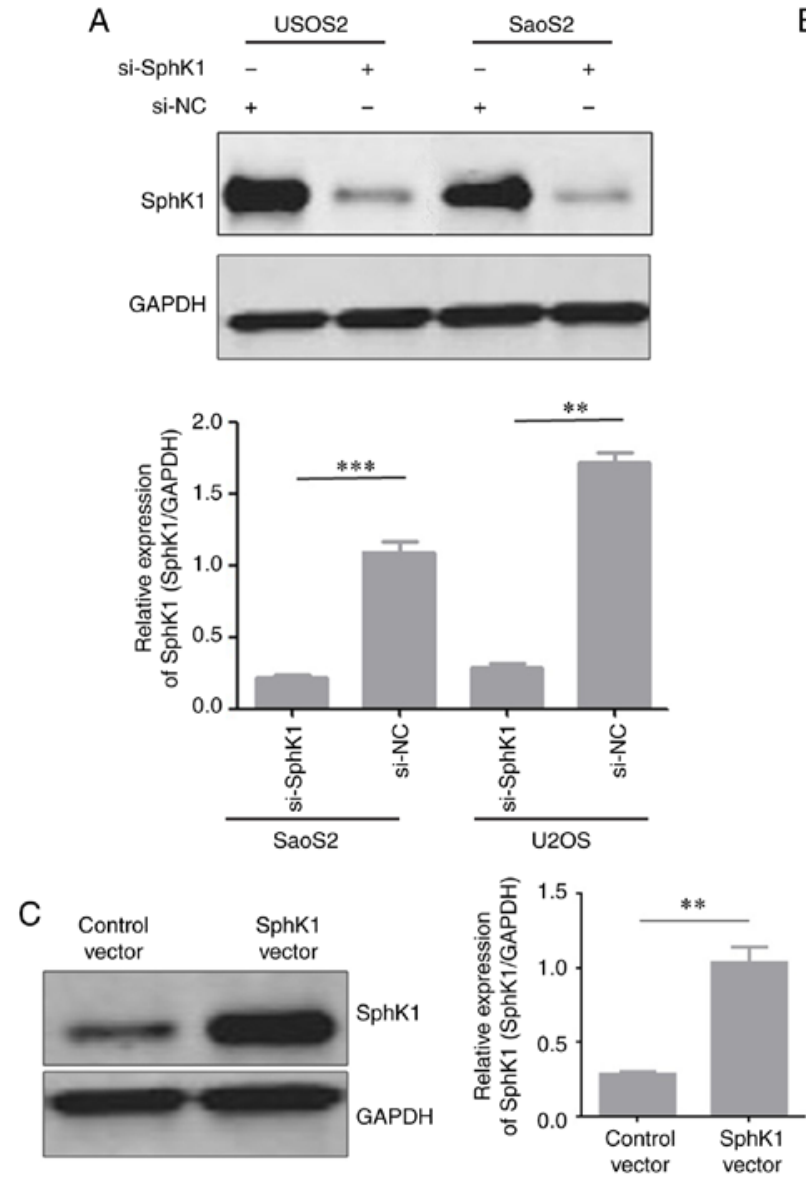

C
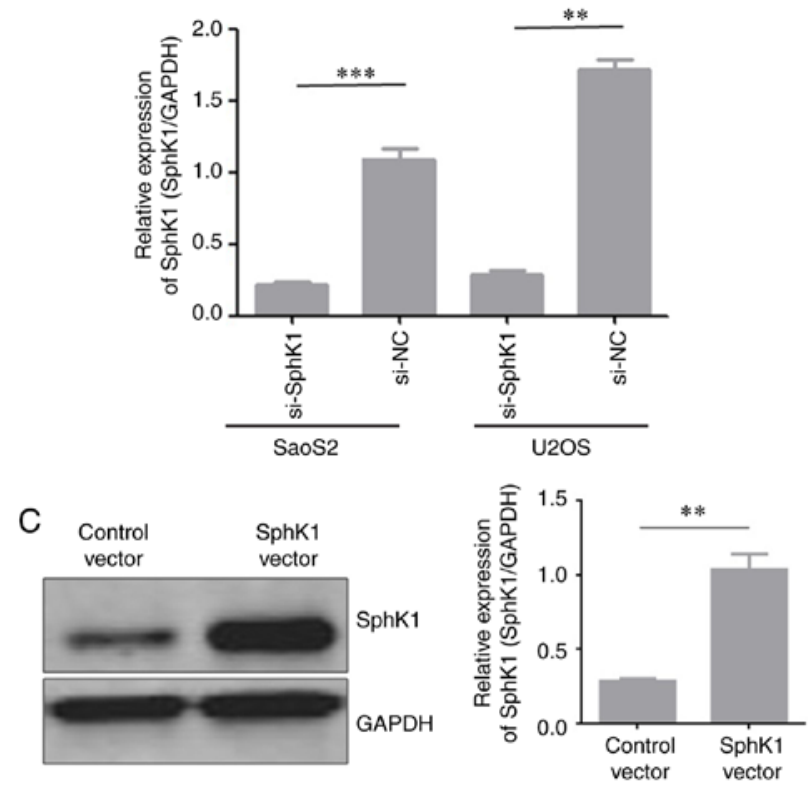
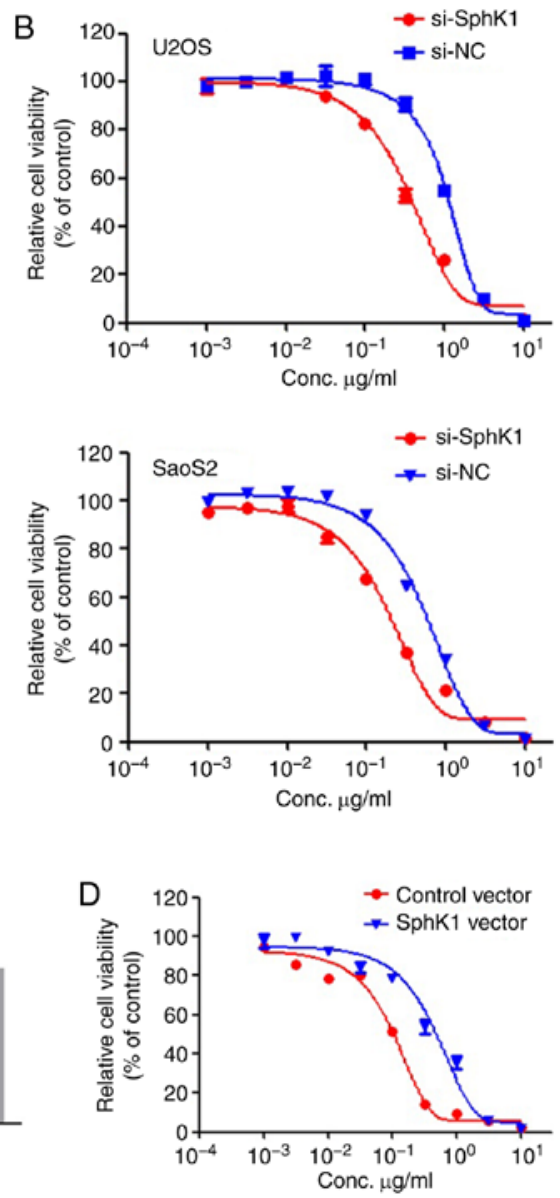

Figure 2. SphK1 is involved in doxorubicin resistance in OS cells. (A) SphK1 expression was significantly decreased by siRNA transfection in U2OS and SaoS2 cells, as indicated by western blotting. (B) The CCK-8 assay was performed to assess cell viability. SphK1 knockdown decreased doxorubicin resistance in both cell lines. (C) Western blotting confirmed that the SphK1 overexpression transfection was successful in MG63 cells. (D) The CCK-8 assay was performed to assess cell viability. SphK1 overexpression increased doxorubicin resistance in MG63 cells. ${ }^{* *} \mathrm{P}<0.01$ and ${ }^{* * *} \mathrm{P}<0.001$. SphK1, sphingosine kinase 1; OS, osteosarcoma; si, small interfering RNA; CCK-8, Cell Counting Kit-8; NC, negative control.
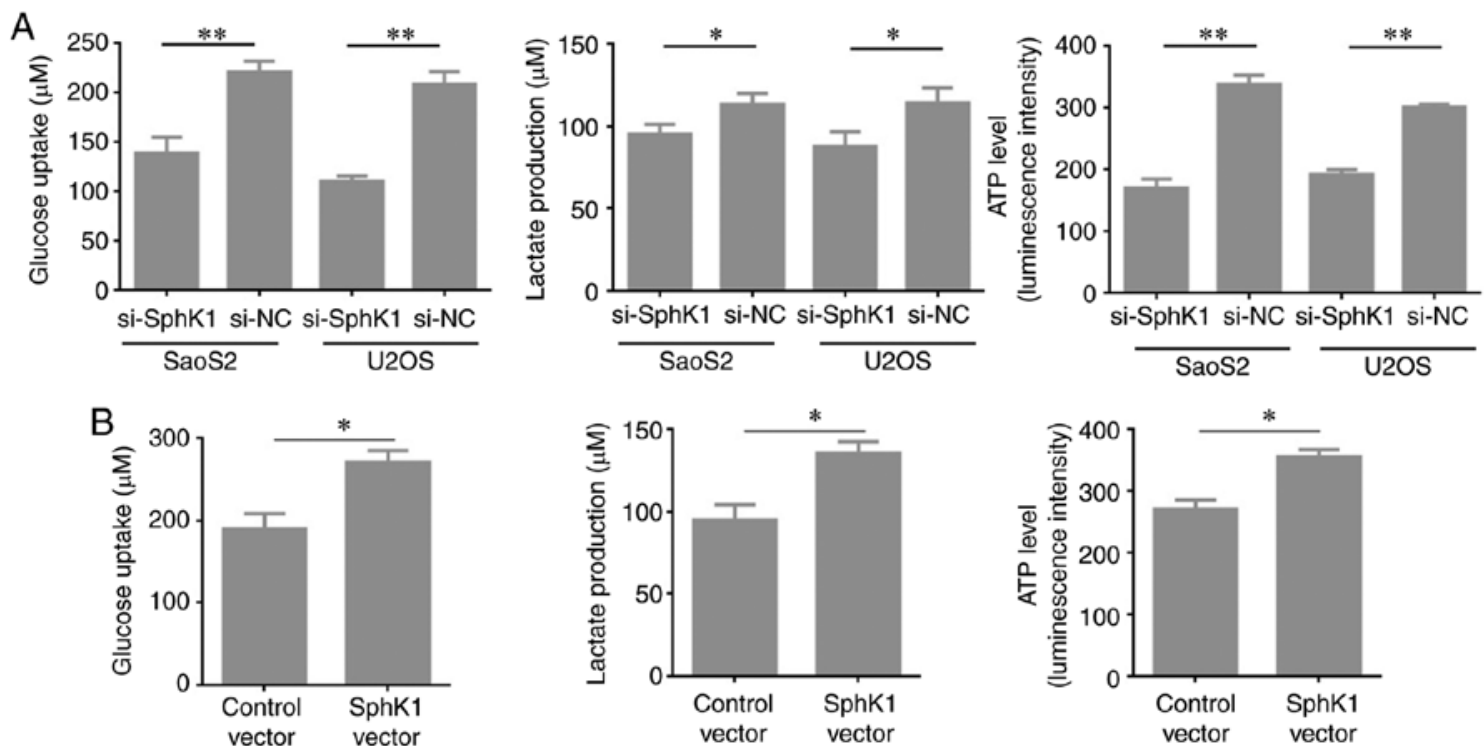

Figure 3. SphK1 is involved in OS cell glycolysis. Glucose uptake, lactate production and cellular ATP levels were determined in (A) U2OS and SaoS2 and (B) MG63 cells. "P<0.05 and ${ }^{* *} \mathrm{P}<0.01$. SphK1, sphingosine kinase 1; OS, osteosarcoma; si, small interfering RNA; NC, negative control. 
A

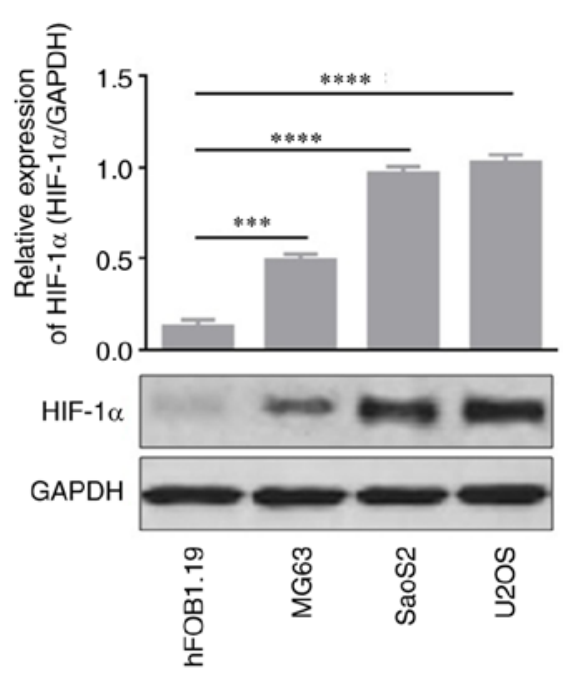

C

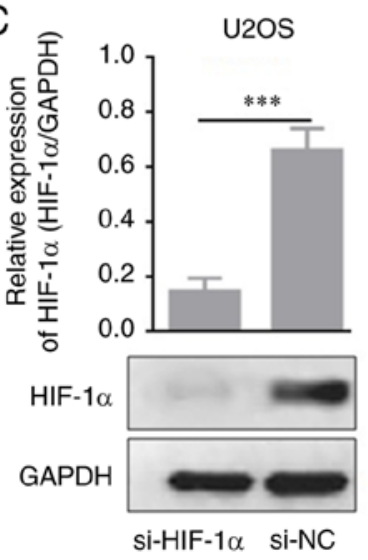

B
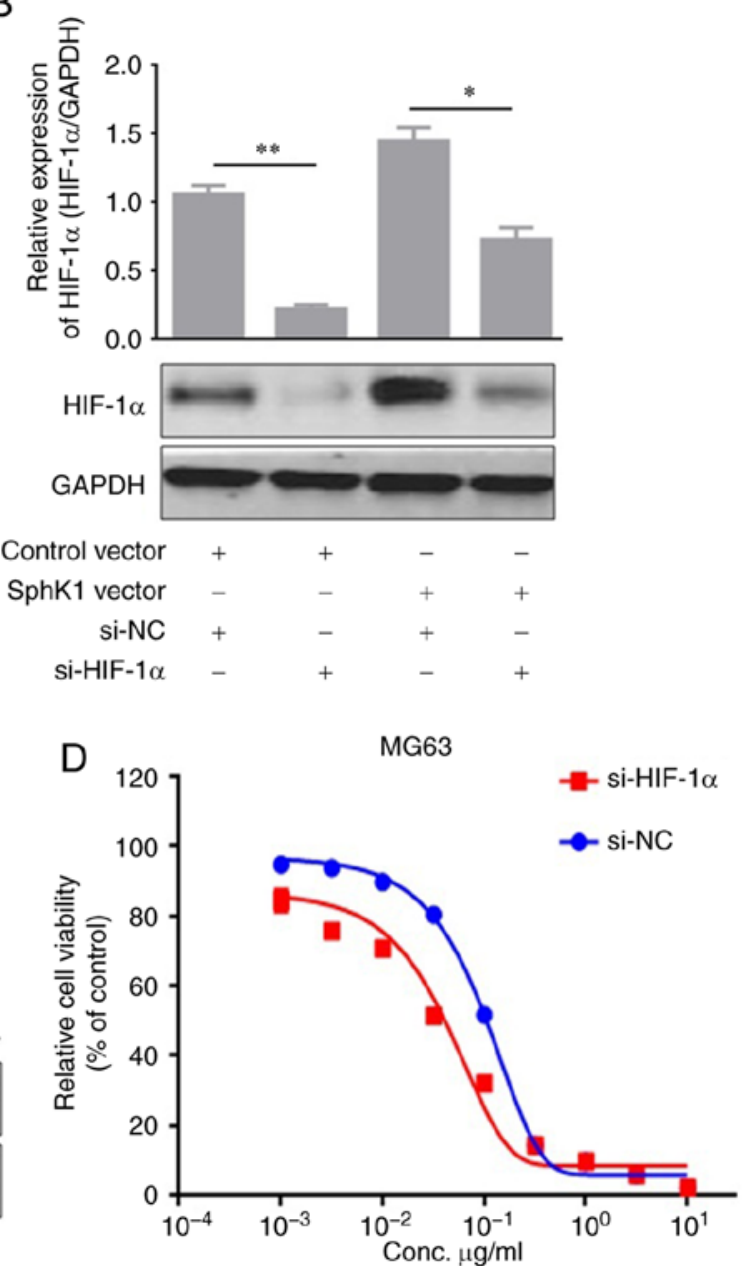

Figure 4. HIF-1 $\alpha$ is involved in SphK1-mediated effects on glycolysis and doxorubicin resistance. (A) Western blotting was used to detect HIF-1 $\alpha$ expression levels in OS cell lines. (B) HIF-1 $\alpha$ expression was regulated by SphK1 expression in MG63 cells. (C) HIF-1 $\alpha$ was knocked down by siRNA transfection in MG63 cells and U2OS cells and confirmed by western blotting. The Cell Counting Kit-8 assay was performed in (D) MG63 cells transfected with si-HIF-1 $\alpha$ to assess cell viability. ${ }^{*} \mathrm{P}<0.05,{ }^{* *} \mathrm{P}<0.01,{ }^{* * *} \mathrm{P}<0.001$ and ${ }^{* * * *} \mathrm{P}<0.0001$. HIF-1 $\alpha$, hypoxia inducible factor- $1 \alpha$; SphK1, sphingosine kinase 1 ; OS, osteosarcoma; si, small interfering RNA; NC, negative control.

cells (Fig. 4F). The decreased glucose uptake, lactate production and cellular ATP levels were also observed in U2OS cells transfected with si-HIF-1 $\alpha$ compared with U2OS control cells (Fig. 4G). The results suggested that the SphK1-mediated effects on glycolysis and doxorubicin resistance were partially mediated by HIF- $1 \alpha$.

\section{Discussion}

In the past 30 years, overall survival time in patients with OS has significantly improved due to clinical administration of aggressive chemotherapies $(2,3)$. However, patients suffering with recurrence or metastasis rarely benefit from advanced chemotherapy regimens, which is partly due to chemoresistance to anti-OS agents (2). The development of chemoresistance in malignancies, including OS, compromises the effectiveness of the majority of chemotherapeutics.

SphK1 has been frequently reported to function as a tumor promoter by supporting cancer cell transformation (7). Increased SphK1 expression has been reported to confer resistance to chemotherapeutic drugs, while restraining SphK1 may restore or improve sensitivity to therapeutics (16-18). In the present study, the role of SphK1 in the chemoresistance of OS cell lines was investigated. Doxorubicin resistance and SphK1 protein expression levels were measured in U2OS, SaoS2 and MG63 cells using a survival assay and western blotting, respectively. The cells that exhibited greater resistance to doxorubicin also exhibited increased levels of SphK1 expression. Furthermore, a number of previous studies have reported that SphK1 expression is increased in cancerous tissues compared with matched non-cancerous tissues $(9,10,13,19-24)$. To further investigate the effects of SphK1 on doxorubicin resistance, SphK1 was knocked down in U2OS and SaoS2 cells by siRNA transfection. SphK1 knockdown in the two OS cell lines decreased the extent of doxorubicin resistance. SphK1 overexpression in MG63 cells, which endogenously expressed low level SphK1 expression, was also performed. Similarly, MG63 cells overexpressing SphK1 exhibited increased doxorubicin resistance compared with the MG63 control cells, and the inhibitory effect of doxorubicin on cell proliferation was also attenuated by increased SphK1 expression levels. Therefore, the role of SphK1 in OS cell chemoresistance was established in the OS cell lines. Furthermore, the association between SphK1 and chemoresistance in other cell lines, 

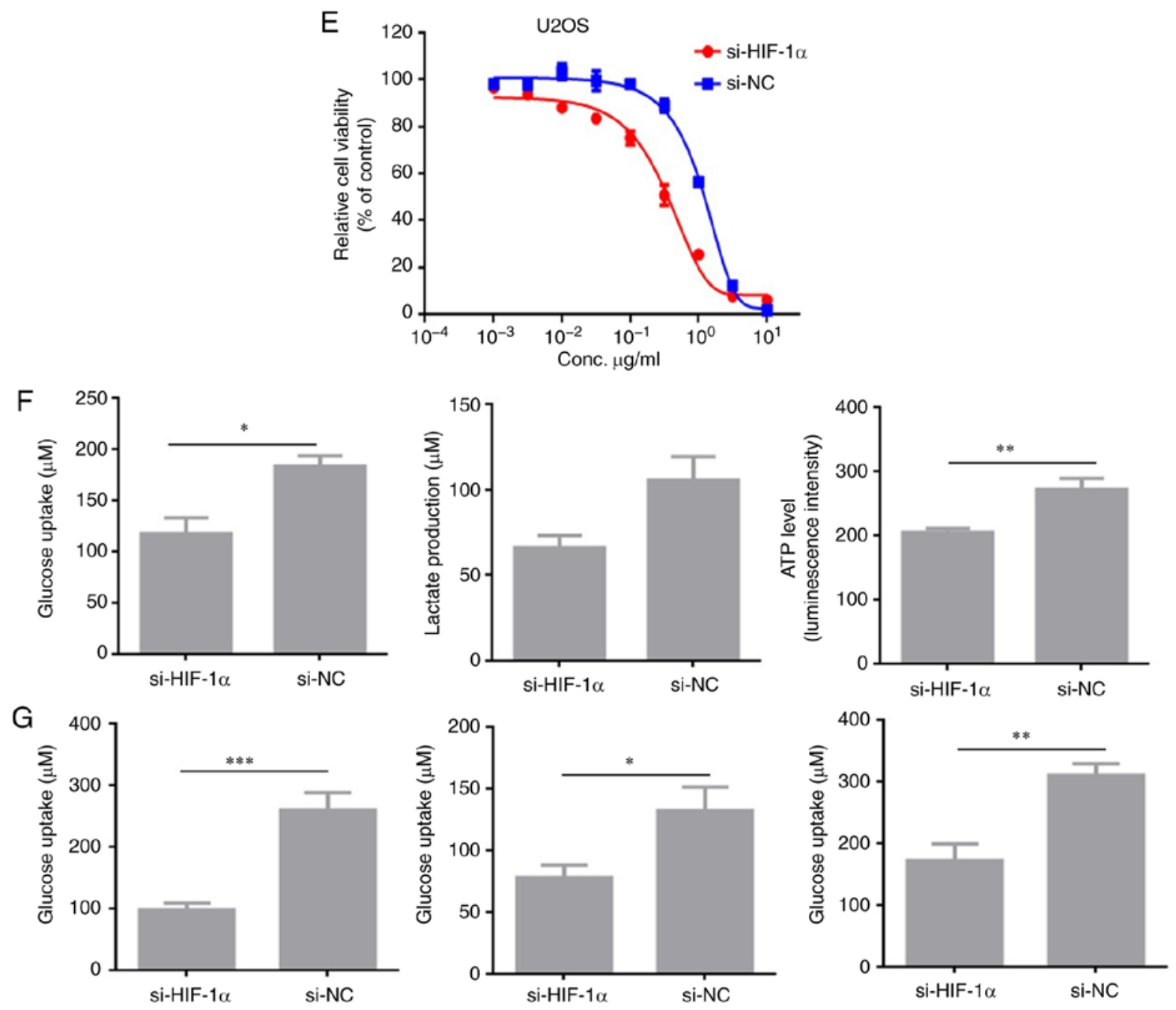

Figure 4. Continued. HIF-1 $\alpha$ is involved in SphK1-mediated effects on glycolysis and doxorubicin resistance. The Cell Counting Kit-8 assay was performed in (E) U2OS cells transfected with si-HIF-1 $\alpha$ to assess cell viability. To investigate glycolysis, glucose uptake, lactate production and cellular ATP levels were measured in (F) MG63 and (G) U2OS cells transfected with si-HIF-1 $\alpha$. "P $<0.05,{ }^{* *} \mathrm{P}<0.01$ and ${ }^{* * * *} \mathrm{P}<0.001$. HIF-1 $\alpha$, hypoxia inducible factor-1 $\alpha$; SphK1, sphingosine kinase 1; OS, osteosarcoma; si, small interfering RNA; NC, negative control.

including those with low level endogenous SphK1 expression, requires further investigation.

In 2006, Bonhoure et al (25) reported that SphK1 contributes to MDR-associated chemoresistance in acute myeloid leukemia. The role of SphK1 in chemoresistance has also been investigated in several different types of cancer, including breast (26), colon (27) and gastroesophageal cancer (28), as well as hepatocellular carcinoma (12). A study conducted by Wang and Wu (12) reported that SphK1 expression was associated with poor prognosis and oxaliplatin resistance in hepatocellular carcinoma (12). Another in vivo study reported that depletion of SphK1 expression inhibited liver tumorigenesis in mice treated with diethyl nitrosamine (11). Katsuta et al (26) demonstrated that inhibiting the activity of SphK1 contributed to doxorubicin-induced cytotoxicity in breast cancer. He et al (1) summarized the molecular mechanisms of chemoresistance in OS; however, the detailed molecular mechanisms by which SphK1 mediates doxorubicin resistance are unknown. Previous studies $(27,29,30)$ reported that activation of the SphK1/ERK/p-ERK signaling pathway in colon cancer cells promoted autophagy, which is one of a number of mechanisms that have been reported to be responsible for chemoresistance.

The tumor environment is characterized by low oxygen levels; therefore, glycolysis is the major source of energy for rapidly proliferating tumor cells. A number of previous studies have reported that SphK1 has a role in the glycolysis of cancer and normal cells $(16,31,32)$. Cuvillier et al (17) also reported that SphK1 may serve as a potential therapeutic target for cancer. Consistently, the present study suggested that increased levels of SphK1 expression promoted glycolysis in OS cells. Therefore, further suggesting that SphK1 may serve as a novel target for the treatment of OS. Subsequently, the underlying mechanisms of SphK1 were investigated and suggested that HIF-1 $\alpha$ expression was required for SphK1-mediated effects on glycolysis and doxorubicin resistance in OS cell lines. HIF-1 $\alpha$, as a responder to hypoxia, has been frequently reported to activate various genes involved in neoangiogenesis, glycolysis, resistance to therapeutics and metastasis $(33,34)$. It has also been reported that HIF-1 $\alpha$ upregulates the expression of multidrug resistance genes (35), and its expression in breast cancer was significantly associated with P-glycoprotein expression, a 
cell membrane protein responsible for the drug efflux $(36,37)$. Upregulation of HIF-1 $\alpha$ in tumor cells was identified as one of the main mechanisms associated with doxorubicin resistance (38). Furthermore, a previous study reported that SphK1 knockdown prevents the accumulation of HIF-1 $\alpha$ in several human cancer cell lines (including PC-3 and U87), suggesting that SphK1 acts as a modulator of HIF-1 $\alpha$ (39). In addition, several studies have reported a number of mechanisms that mediate SphK1-induced doxorubicin resistance. In gastric cancer, SphK1 expression confers resistance to chemotherapeutic-induced apoptosis by stimulating the Akt/forkhead box O3a signaling pathway (18). Additionally, epidermal growth factor receptor was reported to induce chemoresistance in OS (40), and a further investigation reported a relationship between EGFR and SphK1 in resistance to cetuximab treatment (8). Collectively, the aforementioned studies and the present study suggested that SphK1 may serve as a promising therapeutic target for cancer. However, further investigation into the mechanisms of SphK1-induced chemoresistance and glycolysis are required to support the clinical use of SphK1-associated strategies in patients with OS.

To conclude, the present study suggested that SphK1 participated in the development of doxorubicin resistance and glycolysis in OS and indicated that HIF-1 $\alpha$ may be partially responsible for SphK1-induced effects. The results of the present study improved the existing knowledge of the role of SphK1 in OS and further suggested that SphK1 may serve as a potential therapeutic target in the disease.

\section{Acknowledgements}

Not applicable.

\section{Funding}

No funding was received.

\section{Availability of data and materials}

The datasets used and/or analyzed during the current study are available from the corresponding author on reasonable request.

\section{Authors' contributions}

Both authors were involved in writing the manuscript. XR mainly provided the conception and design of the study, and performed the data analysis. CS provided the study materials. Both authors read and approved the final manuscript.

\section{Ethics approval and consent to participate}

Not applicable.

\section{Patient consent for publication}

Not applicable.

\section{Competing interests}

The authors declare that they have no competing interests.

\section{References}

1. He H, Ni J and Huang J: Molecular mechanisms of chemoresistance in osteosarcoma (Review). Oncol Lett 7: 1352-1362, 2014.

2. Ducreux M, Petersen LN, Ohler L, Bergamo F, Metges JP, de Groot JW, Wang JY, García Paredes B, Dochy E, Fiala-Buskies S, et al: Safety and effectiveness of regorafenib in patients with metastatic colorectal cancer in routine clinical practice in the prospective, observational CORRELATE study. Eur J Cancer 123: 146-154, 2019.

3. Morrow JJ and Khanna C: Osteosarcoma genetics and epigenetics: Emerging biology and candidate therapies. Crit Rev Oncog 20: 173-197, 2015.

4. Sun K, Gong C, Peng H, Fang H, Zhou J, Li J, Chen S and Zheng H: High CCL5 expression is associated with osteosarcoma metastasis and poor prognosis of patients with osteosarcoma. Mol Med Rep 16: 6953-6957, 2017.

5. He F, Zhang W, Shen Y, Yu P, Bao Q, Wen J, Hu C and Qiu S: Effects of resection margins on local recurrence of osteosarcoma in extremity and pelvis: Systematic review and meta-analysis. Int J Surg 36: 283-292, 2016.

6. Buljan M, Blattmann P, Aebersold R and Boutros M: Systematic characterization of pan-cancer mutation clusters. Mol Syst Biol 14: e7974, 2018.

7. Heffernan-Stroud LA and Obeid LM: Sphingosine kinase 1 in cancer. Adv Cancer Res 117: 201-235, 2013.

8. Schiefler C, Piontek G, Doescher J, Schuettler D, Mißlbeck M, Rudelius M, Haug A, Reiter R, Brockhoff G and Pickhard A: Inhibition of SphK1 reduces radiation-induced migration and enhances sensitivity to cetuximab treatment by affecting the EGFR/SphK1 crosstalk. Oncotarget 5: 9877-9888, 2014.

9. Wang S, Liang Y, Chang W, Hu B and Zhang Y: Triple negative breast cancer depends on Sphingosine Kinase 1 (SphK1)/Sphingosine-1-Phosphate (S1P)/Sphingosine 1-phosphate receptor 3 (S1PR3)/notch signaling for metastasis. Med Sci Monit 24: 1912-1923, 2018.

10. Hatoum D, Haddadi N, Lin Y, Nassif NT and McGowan EM: Mammalian sphingosine kinase (SphK) isoenzymes and isoform expression: Challenges for SphK as an oncotarget. Oncotarget 8: 36898-36929, 2017.

11. Chen J, Qi Y, Zhao Y, Kaczorowski D, Couttas TA, Coleman PR, Don AS, Bertolino P, Gamble JR, Vadas MA, et al: Deletion of sphingosine kinase 1 inhibits liver tumorigenesis in diethylnitrosamine-treated mice. Oncotarget 9: 15635-15649, 2018.

12. Wang $\mathrm{F}$ and $\mathrm{Wu} \mathrm{Z}$ : Sphingosine kinase 1 overexpression is associated with poor prognosis and oxaliplatin resistance in hepatocellular carcinoma. Exp Ther Med 15: 5371-5376, 2018.

13. Zhao Z, Ma J, Hu B, Zhang Y and Wang S: SPHK1 promotes metastasis of thyroid carcinoma through activation of the S1P/S1PR3/Notch signaling pathway. Exp Ther Med 15: 5007-5016, 2018.

14. Madhunapantula SV, Hengst J, Gowda R, Fox TE, Yun JK and Robertson GP: Targeting sphingosine kinase-1 to inhibit melanoma. Pigment Cell Melanoma Res 25: 259-274, 2012.

15. Gault CR and Obeid LM: Still benched on its way to the bedside: Sphingosine kinase 1 as an emerging target in cancer chemotherapy. Crit Rev Biochem Mol Biol 46: 342-351, 2011.

16. Sun K, Zhang Y,D'Alessandro A, Nemkov T, Song A, Wu H, Liu H, Adebiyi M, Huang A, Wen YE, et al: Sphingosine-1-phosphate promotes erythrocyte glycolysis and oxygen release for adaptation to high-altitude hypoxia. Nat Commun 7: 12086, 2016.

17. Cuvillier O, Ader I, Bouquerel P, Brizuela L, Gstalder C and Malavaud B: Hypoxia, therapeutic resistance, and sphingosine 1-phosphate. Adv Cancer Res 117: 117-141, 2013.

18. Xiong $\mathrm{H}$, Wang J, Guan $\mathrm{H}$, Wu J, Xu R, Wang M, Rong X, Huang K, Huang J, Liao Q, et al: SphK1 confers resistance to apoptosis in gastric cancer cells by downregulating Bim via stimulating Akt/FoxO3a signaling. Oncol Rep 32: 1369-1373, 2014.

19. Bao Y, Guo Y, Zhang C, Fan F and Yang W: Sphingosine Kinase 1 and Sphingosine-1-phosphate signaling in colorectal cancer. Int J Mol Sci 18: 2109, 2017.

20. Li W, Li J, Wang Y, Zhang K, Li N, Tian Z, Ni B, Wang H and Ruan Z: Sphingosine kinase 1 is a potential therapeutic target for nasopharyngeal carcinoma. Oncotarget 7: 80586-80598, 2016.

21. Lu PH, Chen MB, Liu YY, Wu MH, Li WT, Wei MX, Liu CY and Qin SK: Identification of sphingosine kinase 1 (SphK1) as a primary target of icaritin in hepatocellular carcinoma cells. Oncotarget 8: 22800-22810, 2017. 
22. Yao C, Wu S, Li D, Ding H, Wang Z, Yang Y, Yan S and Gu Z: Co-administration phenoxodiol with doxorubicin synergistically inhibit the activity of sphingosine kinase-1 (SphK1), a potential oncogene of osteosarcoma, to suppress osteosarcoma cell growth both in vivo and in vitro. Mol Oncol 6: 392-404, 2012.

23. Livak KJ and Schmittgen TD: Analysis of relative gene expression data using real-time quantitative PCR and the 2(-Delta Delta C (T)) method. Methods 25: 402-408, 2001.

24. Nazouri AS, Asadpour O, Dabiri S, Pourseyedi B, Lashkarizadeh MR and Zianalinejad H: High expression of sphingosine kinase 1 in estrogen and progesterone receptors-negative breast cancer. Iran J Pathol 12: 218-224, 2017.

25. Bonhoure E, Pchejetski D, Aouali N, Morjani H, Levade T, Kohama $\mathrm{T}$ and Cuvillier O: Overcoming MDR-associated chemoresistance in HL-60 acute myeloid leukemia cells by targeting sphingosine kinase-1. Leukemia 20: 95-102, 2006.

26. Katsuta E, Yan L, Nagahashi M, Raza A, Sturgill JL, Lyon DE, Rashid OM, Hait NC and Takabe K: Doxorubicin effect is enhanced by sphingosine-1-phosphate signaling antagonist in breast cancer. J Surg Res 219: 202-213, 2017.

27. Xu C, Zhang W, Liu S, Wu W, Qin M and Huang J: Activation of the SphK1/ERK/p-ERK pathway promotes autophagy in colon cancer cells. Oncol Lett 15: 9719-9724, 2018.

28. Matula K, Collie-Duguid E, Murray G, Parikh K, Grabsch H, Tan P, Lalwani S, Garau R, Ong Y, Bain G, et al: Regulation of cellular sphingosine-1-phosphate by sphingosine kinase 1 and sphingosine-1-phopshate lyase determines chemotherapy resistance in gastroesophageal cancer. BMC Cancer 15: 762, 2015.

29. Meng Y, Gao R, Ma J, Zhao J, Xu E, Wang C and Zhou X: MicroRNA-140-5p regulates osteosarcoma chemoresistance by targeting HMGN5 and autophagy. Sci Rep 7: 416, 2017.

30. Kim M, Jung JY, Choi S, Lee H, Morales LD, Koh JT, Kim SH, Choi YD, Choi C, Slaga TJ, et al: GFRA1 promotes cisplatin-induced chemoresistance in osteosarcoma by inducing autophagy. Autophagy 13: 149-168, 2017.

31. Bernacchioni C, Ghini V, Cencetti F, Japtok L, Donati C, Bruni P and Turano P: NMR metabolomics highlights sphingosine kinase-1 as a new molecular switch in the orchestration of aberran metabolic phenotype in cancer cells. Mol Oncol 11: 517-533, 2017.

32. Watson DG, Tonelli F, Alossaimi M, Williamson L, Chan E, Gorshkova I, Berdyshev E, Bittman R, Pyne NJ and Pyne S: The roles of sphingosine kinases 1 and 2 in regulating the Warburg effect in prostate cancer cells. Cell Signal 25: 1011-1017, 2013.
33. Ma Q, Zhang Y, Liu T, Jiang K, Wen Y, Fan Q and Qiu X: Hypoxia promotes chemotherapy resistance by down-regulating SKA1 gene expression in human osteosarcoma. Cancer Biol Ther 18: 177-185, 2017.

34. Sowa T, Menju T, Chen-Yoshikawa TF, Takahashi K, Nishikawa S, Nakanishi T, Shikuma K, Motoyama H, Hijiya K, Aoyama A, et al: Hypoxia-inducible factor 1 promotes chemoresistance of lung cancer by inducing carbonic anhydrase IX expression. Cancer Med 6: 288-297, 2017.

35. Badowska-Kozakiewicz AM, Sobol M and Patera J: Expression of multidrug resistance protein $\mathrm{P}$-glycoprotein in correlation with markers of hypoxia (HIF-1 $\alpha$, EPO, EPO-R) in invasive breast cancer with metastasis to lymph nodes. Arch Med Sci 13: 1303-1314, 2017

36. Xie Y and Zhong DW: AEG-1 is associated with hypoxia-induced hepatocellular carcinoma chemoresistance via regulating PI3K/AKT/HIF-1alpha/MDR-1 pathway. Excli J 15: 745-757, 2016.

37. Doublier S, Belisario DC, Polimeni M, Annaratone L, Riganti C, Allia E, Ghigo D, Bosia A and Sapino A: HIF-1 activation induces doxorubicin resistance in MCF7 3-D spheroids via P-glycoprotein expression: A potential model of the chemo-resistance of invasive micropapillary carcinom of the breast. BMC Cance 12: 4, 2012.

38. Cao Y, Eble JM, Moon E, Yuan H, Weitzel DH, Landon CD, Nien CY, Hanna G, Rich JN, Provenzale JM and Dewhirst MW: Tumor cells upregulate normoxic HIF-1 $\alpha$ in response to doxorubicin. Cancer Res 73: 6230-6242, 2013.

39. Ader I, Brizuela L, Bouquerel P, Malavaud B and Cuvillier O: Sphingosine kinase 1: A new modulator of hypoxia inducible factor 1alpha during hypoxia in human cancer cells. Cancer Res 68: 8635-8642, 2008.

40. Sevelda F, Mayr L, Kubista B, Lötsch D, van Schoonhoven S, Windhager R, Pirker C, Micksche M and Berger W: EGFR is not a major driver for osteosarcoma cell growth in vitro but contributes to starvation and chemotherapy resistance. J Exp Clin Cancer Res 34: 134, 2015.

This work is licensed under a Creative Commons Attribution-NonCommercial-NoDerivatives 4.0 International (CC BY-NC-ND 4.0) License. 